\title{
Nuclear transfer technique affects mRNA abundance, developmental competence and cell fate of the reconstituted sheep oocytes
}

\author{
F Moulavi ${ }^{1}$, S M Hosseini ${ }^{1}$, M Hajian ${ }^{1}$, M Forouzanfar ${ }^{1}$, P Abedi $^{1}$, S Ostadhosseini ${ }^{1}$, V Asgari $^{1}$ \\ and $\mathrm{MH}$ Nasr-Esfahani ${ }^{1,2}$ \\ ${ }^{1}$ Department of Reproductive Biology, Reproductive Biomedicine Research Center, Royan Institute for Biotechnology, \\ ACECR, Isfahan, Iran and ${ }^{2}$ Department of Embryology, Reproductive Biomedicine Research Center, Royan Institute for \\ Reproductive Biomedicine, ACECR, Reproductive Biomedicine Research Center, Tehran, Iran
}

Correspondence should be addressed to M H Nasr-Esfahani at Department of Reproductive Biology, Reproductive Biomedicine Research Center, Royan Institute for Biotechnology, ACECR; Email: mh.nasr-esfahani@royaninstitute.org

\begin{abstract}
The effect of technical steps of somatic cell nuclear transfer (SCNT) on different aspects of cloned embryo development was investigated in sheep. In vitro-matured oocytes were enucleated in the presence or absence of zona and reconstituted by three different SCNT techniques: conventional zona-intact (ZI-NT), standard zona-free (ZF-NT) and intracytoplasmic nuclear injection (ICI-NT). Stepwise alterations in nuclear remodeling events and in mRNA abundances, throughput and efficiency of cloned embryo development and cell allocation of the resulted blastocysts were assessed. Early signs of nuclear remodeling were observed as soon as $\mathbf{2} \mathbf{h}$ post-reconstitution (hpr) for fusion-based methods of nuclear transfer (ZI-NT and ZF-NT) but were not observable until 4 hpr with the ICI-NT method. The relative mRNA abundances of HSP9OAA1 (HSP90), NPM2 and ATPase genes were not affected by i) presence or absence of zona, ii) oocyte enucleation method and iii) nuclear transfer method. After reconstitution, however, the relative mRNA contents of POU5F1 (OCT4) with the ZI-NT and ZF-NT methods and of PAPOLA (PAP) with ZF-NT were significantly lower than those for the ICI-NT method. Zona removal doubled the throughput of cloned blastocyst development for the ZF-NT technique compared with ZI-NT and ICI-NT. Cleavage rate was not affected by the SCNT protocol, whereas blastocyst yield rate in ICI-NT technique (17.0 $\pm 1.0 \%)$ was significantly $(P<0.05 ;$ ANOVA) higher than in ZF-NT $(7.1 \pm \mathbf{1 . 5} \%)$ but not in the ZI-NT group $(\mathbf{1 1 . 2} \pm 3.3 \%)$. Despite the similarities in total cell number, SCNT protocol changed the distribution of cells in the blastocysts, as ZF-NT-cloned blastocysts had significantly smaller inner cell mass than ZI-NT. These results indicate that technical aspects of cloning may result in the variety of cloning phenotypes.
\end{abstract}

Reproduction (2013) 145 345-355

\section{Introduction}

Although conceptually simple, the technique of somatic cell nuclear transfer (SCNT) has proven a demanding multistep process in practice. Furthermore, the overall efficiency of SCNT technique, in terms of live birth rate per transferred embryos, is low with potential perturbation in development occurring at all steps (Wells et al. 2004). Importantly, the investigation of biological factors underlying low cloning efficiency has been hampered by technical aspects of the cloning procedure (Oback et al. 2003).

In order to increase the efficiency and throughput of cloning process a wide range of cloning techniques have been developed and introduced over the time (for review, see Verma \& Trounson (2006)). Importantly, a growing body of evidence indicates that certain SCNT techniques may be more efficient in certain species.
For example, Wakayama et al. (1998) demonstrated that employing a non-fusion piezo-actuated method of embryo reconstitution and prolonged exposure of donor nuclei $(1-6 h)$ to the recipient cytoplasm rich in metaphase-promoting factor (MPF) were their keys to success in cloning mice. High MPF activity induces nuclear envelope breakdown (NEBD) via p34 ${ }^{\text {cdc2 }}$ kinaserelated phosphorylation of lamin, which is a nuclear membrane protein (Peter et al. 1990). This in turn facilitates subsequent nuclear remodeling changes including premature chromosome condensation (PCC), nuclear swelling and microtubule organization (Latham 2005, Sung et al. 2007).

While the role of nuclear remodeling in successful reprogramming and clonal development is well documented (Mitalipov et al. 2007), there is ongoing serious debate about whether MPF activity is an absolute necessity for oocyte-mediated 
reprogramming (Sung et al. 2007). In this regard and despite some studies emphasizing the essentiality of MPF for reprogramming of donor nuclei (Wakayama et al. 1998, Zhou et al. 2006), there are indications that high MPF activity is not important, as viable offspring have been produced after nuclear transfer into cytoplasm of preactivated oocytes (Sung et al. 2007), and even early zygotes (Schurmann et al. 2006). Even though, this contradiction may be a reflection of either different SCNT techniques used or species-specific variations in the nuclear remodeling events. Therefore, a clear understanding of how SCNT technique may affect reprogramming and cloned embryo development in a given species may shed some light on this ambiguity.

It has been demonstrated that the protocol used for SCNT in terms of fusion-activation timing affects the pattern of gene expression and developmental competence of cloned embryos (Wrenzycki et al. 2001). Our recent studies on epigenetic modification of donor cells and cloned embryos well showed that any change in compartmentalization of the chromatin leads to manifest changes in the transcription status and developmental competence of bovine cloned embryos (Jafari et al. 2011a, 2011b, Jafarpour et al. 2011). In primates, Zhou et al. (2006) showed that monkey oocytes are particularly vulnerable to premature activation and MPF degradation. Accordingly, they developed a modified one-step micromanipulation protocol to prevent premature cytoplast activation during SCNT, which resulted in robust NEBD and PCC with high cloned blastocyst development for the first time in non-human primates.

These observations further indicate that each mammalian species may respond differently to a given technique. However, owing to the multistep nature of the cloning process, it is believed that the exact contribution of each step to overall cloning success must be determined in comparative studies (Oback \& Wells 2002). This requires strict comparison between different steps in a single study, and application of stringent identification criteria in order to obtain a final conclusion. In this study, we investigate how different steps of three SCNT techniques may affect different aspects of in vitro clone embryo development in sheep.
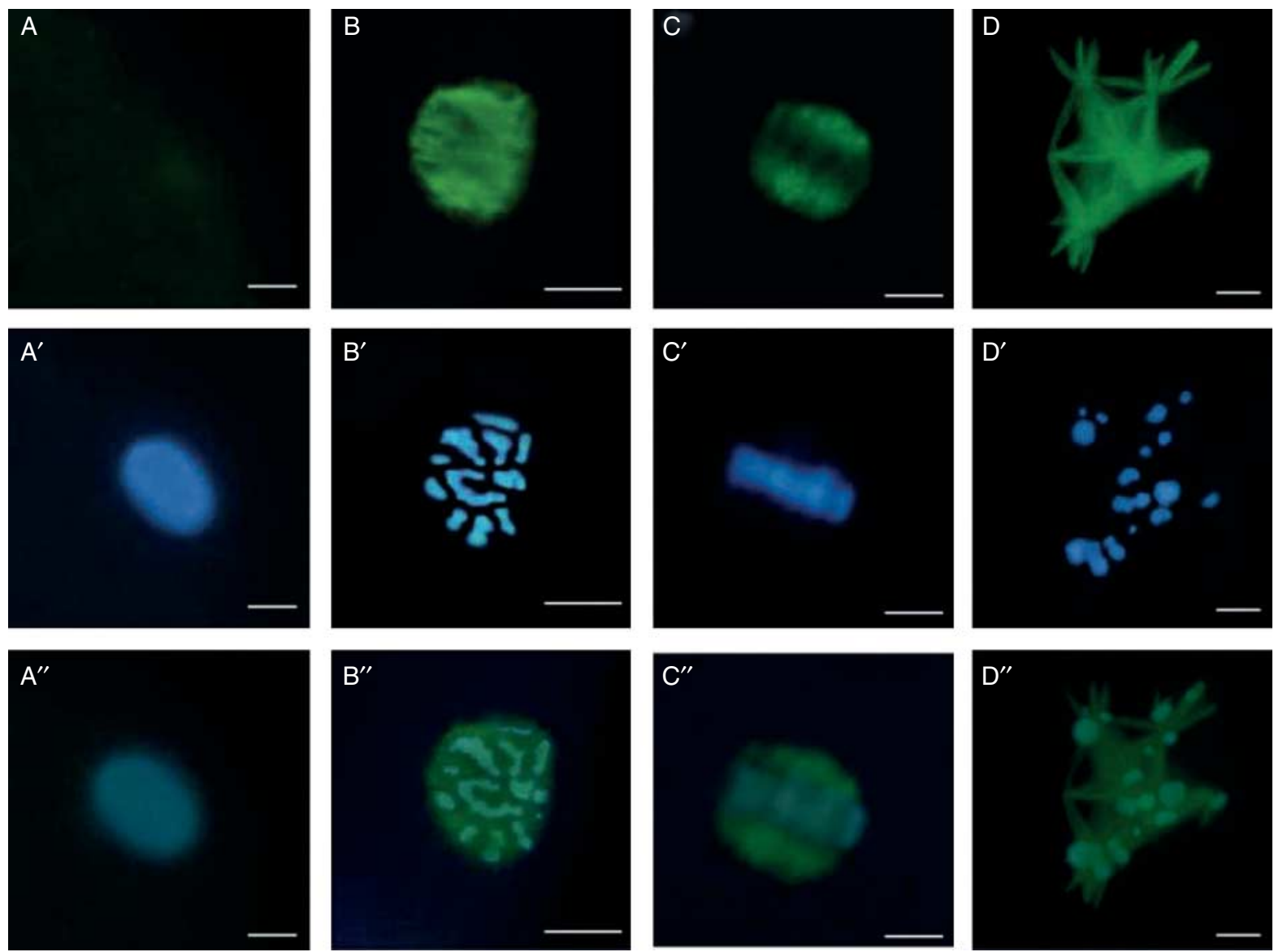

Figure 1 Representative images showing different organizations of microtubules $(A, B, C$ and $D)$, chromosomes $\left(A^{\prime}, B^{\prime}, C^{\prime}\right.$ and $\left.D^{\prime}\right)$, and the merged images showing the organizations of both microtubules and chromosomes $\left(A^{\prime \prime}, B^{\prime \prime}, C^{\prime \prime}\right.$ and $\left.D^{\prime \prime}\right)$. $\left(A, A^{\prime}\right.$ and $\left.A^{\prime \prime}\right)$ No sign of nuclear swelling or spindle formation, $\left(B, B^{\prime}\right.$ and $\left.B^{\prime \prime}\right)$ PCC with early developing spindle, $\left(C, C^{\prime}\right.$ and $\left.C^{\prime \prime}\right)$ bipolar spindle $(C)$ and complete chromosome $\left(C^{\prime}\right)$ organization, $\left(\mathrm{D}, \mathrm{D}^{\prime}\right.$ and $\left.\mathrm{D}^{\prime \prime}\right)$ multipolar spindle (D) and aberrant chromosome $\left(\mathrm{D}^{\prime}\right)$ organization. Bars represent $100 \mu \mathrm{m}$ in all images. 


\section{Results}

\section{Nuclear remodeling}

As shown in Figs 1 and 2, the SCNT protocol had a time-dependent effect on kinetic of nuclear remodeling. Accordingly, at $2 \mathrm{~h}$ post-reconstitution (hpr), the majority of the nuclei used in the ICI-NT approach remained intact with minor signs of bipolar spindle formation. At the same time, however, reasonable proportions of oocytes reconstituted via the ZI-NT and ZF-NT approaches showed signs of remodeling and had either swollen (28.5 and $30.0 \%$ respectively) or prematurely condensed (17.1 and $40.0 \%$ respectively) nuclei with bipolar spindles. The PCC rate of oocytes reconstituted by the ZF-NT approach was also significantly higher than that for the ZI-NT technique. At $4 \mathrm{hpr}$, however, the overall incidence rates of nuclear remodeling were not different between the SCNT protocols. Furthermore irrespective of the SCNT protocol, the majority of the reconstituted oocytes had prematurely condensed chromosomes on well-structured bipolar spindles. Even though PCC rates of ZI-NT and ZF-NT were significantly higher than that for the ICI-NT method. At $6 \mathrm{hpr}$ the overall percentages of nuclear remodeling were not significantly different between the SCNT groups and were comparable to nuclear remodeling events observed at $4 \mathrm{hpr}$ as well. However, the frequencies of abnormal nuclear remodeling significantly increased at $6 \mathrm{hpr}$. Accordingly, approximately half of the reconstituted oocytes with remodeled nuclei revealed chromosomal aberrations and multipolar spindles.

\section{Quantitative competitive real-time PCR (qCRT-PCR)}

As shown in Fig. 3, qcRT-PCR showed that almost all oocyte manipulations have decreasing effects on relative abundances of maternal mRNA, though the effects of different SCNT techniques and different steps of each technique were not the same. Even though, the relative mRNA abundances of three genes (HSP9OAA1 (HSP9O),

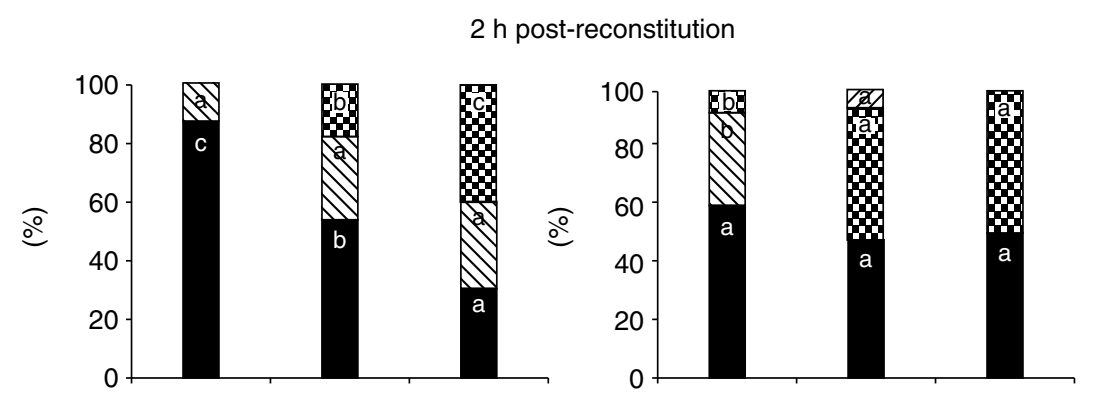

$4 \mathrm{~h}$ post-reconstitution

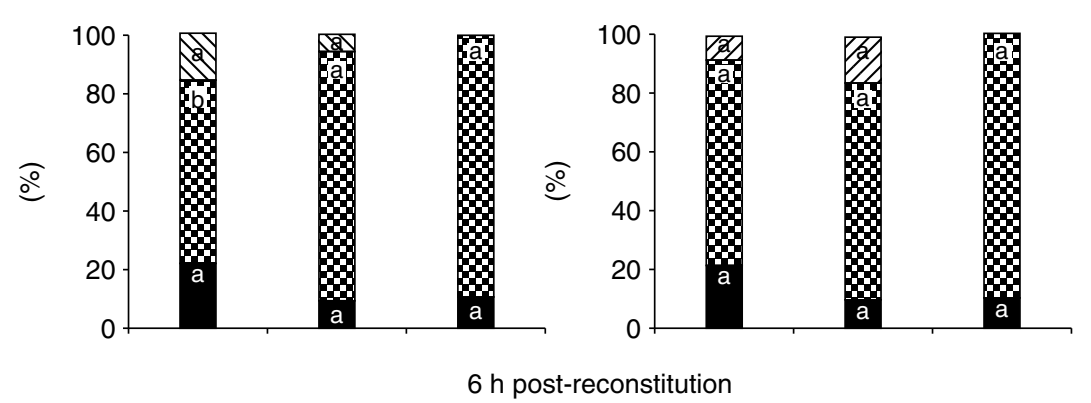

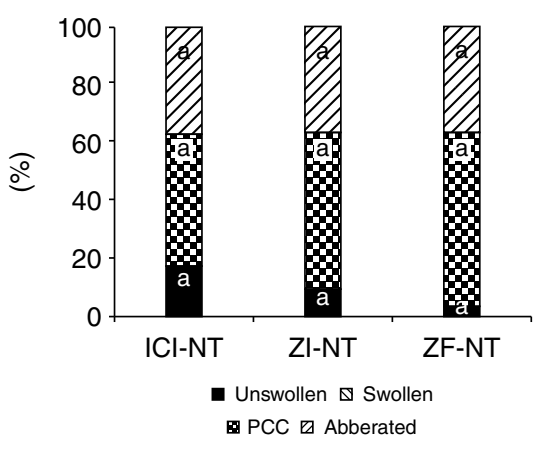

Chromosome organization

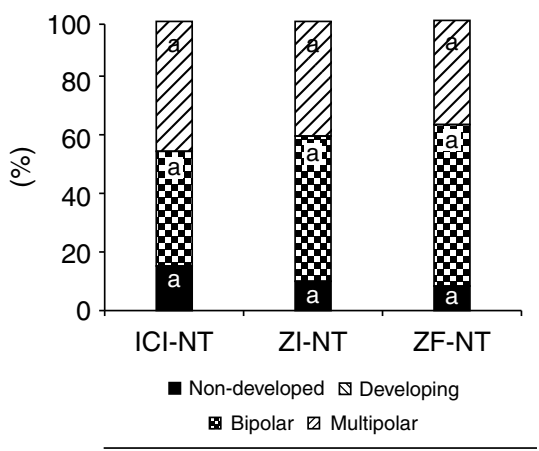

Microtubule organization
Figure 2 Time-dependent effect of SCNT technique on remodeling events of the reconstituted oocytes. Values with different letters are significantly different at $P<0.05$. 

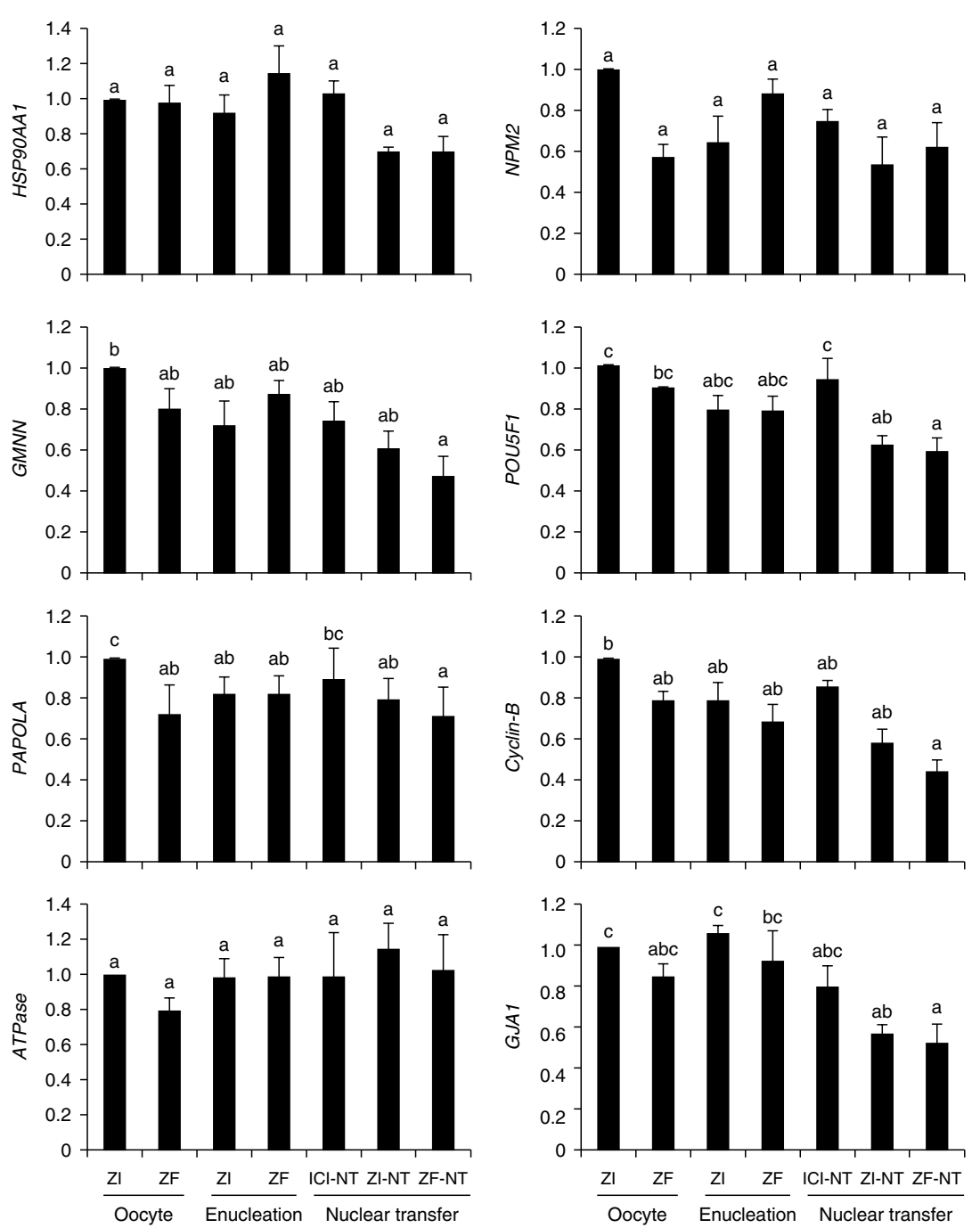

Figure 3 Effect of different steps of SCNT on relative mRNA abundance of in vitro matured sheep oocytes. Values with at least one common letter are not significantly different at $P<0.05$.

nucleoplasmin 2 (NPM2), and ATPase) remained nearly constant during SCNT and were not affected by i) presence or absence of zona, ii) cytochalasin-B (CB) treatment of oocytes (in ICI-NT and ZI-NT techniques), iii) oocyte enucleation method and iv) nuclear transfer method.

The most important decreases in mRNA were observed during the nuclear transfer step. In this sense, fusion-based methods of nuclear transfer (ZI-NT and ZF-NT) had overall more reductions in relative abundances of mRNA compared with non-fusion-based method (ICI-NT). For example, in ZF-NT oocytes, the relative mRNA abundances of five genes (Geminin (GMNN), POU5F1 (OCT4), poly-A polymerase (PAPOLA (PAP)), cyclin-B, and GJA1 (CX43)) were significantly lower than those in zona-intact (control) oocytes. Moreover, the relative abundances of POU5F1, PAPOLA and GJA1 in ZI-NT oocytes were significantly lower than those in control oocytes. Importantly, the relative mRNA contents of $P O U 5 F 1$ in ZI-NT and ZF-NT oocytes and of PAPOLA in ZF-NT oocytes were

significantly lower than those in ICI-NT oocytes. None of the manipulations affected the relative abundances of housekeeping genes (GAPDH and $\beta$-actin).

\section{Yield and quality of embryo development}

As shown in Table 1, within the SCNT groups, $14.9 \pm 1.2 \%$ of oocytes in the ICI-NT group were found to be degenerated/fragmented, a rate that was significantly higher than that for the ZF-NT method $(7.2 \pm 1.9 \%)$, and non-significantly higher than that for the ZI-NT method $(9.4 \pm 1.6 \%)$. Cleavage rates were not affected by the SCNT protocol, and the percentages of cleaved embryos advanced to morula were not significantly different between the three SCNT techniques, except for morula rate of ZF-NT, which was significantly lower than that for the ZI-NT group. However, blastocyst yield using ICI-NT $(17.0 \pm 1.0 \%)$ was significantly higher than for ZF-NT $(7.1 \pm 1.5 \%)$, but not ZI-NT (11.2 $\pm 3.3 \%)$. Importantly, the relative efficiencies of cloned blastocyst development, based on the total number of oocytes used, were not significantly different between the SCNT groups. 
Table 1 Effect of method of embryo production (SCNT, PA and IVF), technique of SCNT (ICI-NT, ZI-NT and ZF-NT), and presence/absence of zona in parthenogenetic embryos on yield, efficiency and quality of in vitro embryo development in sheep.

\begin{tabular}{|c|c|c|c|c|c|c|c|c|c|}
\hline \multirow[b]{2}{*}{$\begin{array}{l}\text { Experi- } \\
\text { ments }\end{array}$} & \multirow[b]{2}{*}{$\begin{array}{c}\text { Oocyte } \\
(n)\end{array}$} & \multirow[b]{2}{*}{$\begin{array}{c}\text { Frag/deg } \\
(\% \pm \text { s.E.M. })\end{array}$} & \multicolumn{3}{|c|}{$\begin{array}{c}\text { Number (\% } \% \text { S.E.M.) } \\
\text { of embryos developed }\end{array}$} & \multirow[b]{2}{*}{$\begin{array}{c}\text { Cloning } \\
\text { efficiency }\end{array}$} & \multicolumn{3}{|c|}{ Differential staining } \\
\hline & & & Cleavage & Morula & Blastocyst $^{\mathrm{a}}$ & & $\begin{array}{c}\text { TCN } \\
(n \pm \text { s.E.M. })\end{array}$ & $\begin{array}{l}\text { ICM/TCN } \\
(\% \pm \text { s.E.M. })\end{array}$ & $\begin{array}{c}\text { TE/TCN } \\
(\% \pm \text { s.E.M. }) \\
\end{array}$ \\
\hline \multicolumn{10}{|l|}{ SCNT } \\
\hline ICI-NT & 290 & $44(14.9 \pm 1.2)^{\S}$ & $162(55.6 \pm 5.1)^{*,+}$ & $40(25.2 \pm 2.5)^{*,+}$ & $28(17.0 \pm 1.0)^{+}$ & $9.5 \pm 1.3 *$ & $120.2 \pm 7.8^{*}$ & $19.4 \pm 1.8^{+, \neq}$ & $80.5 \pm 1.8^{*, t, \neq}$ \\
\hline ZI-NT & 220 & $22(9.4 \pm 1.6)^{t, \neq, \S}$ & $112(51.3 \pm 3.0)^{*}$ & $46(40.6 \pm 4.6)^{t, \pm}$ & $12(11.2 \pm 3.3)^{*,+}$ & $4.4 \pm 2.2^{*}$ & $116.3 \pm 7.8^{*}$ & $24.1 \pm 1.8^{\ddagger}$ & $75.8 \pm 1.8^{*,+}$ \\
\hline ZF-NT & 260 & $20(7.2 \pm 1.9)^{t, \pm}$ & $164(63.2 \pm 3.3)^{*,+, \neq}$ & $32(18.9 \pm 2)^{*}$ & $12(7.0 \pm 1.5)^{*}$ & $4.6 \pm 1.2 *$ & $100.8 \pm 5.1 *$ & $12.9 \pm 1.2^{*,+}$ & $87.1 \pm 1.2^{\neq, \S}$ \\
\hline \multicolumn{10}{|l|}{ PA } \\
\hline ZI-PA & 215 & $10(4.8 \pm 0.8)^{*,+}$ & $188(87.2 \pm 2.9)^{\S}$ & $116(62.5 \pm 4.7)^{\S}$ & $66(35.7 \pm 3.1)^{\ddagger}$ & $31.0 \pm 2.2^{+}$ & $190 \pm 13.0^{+}$ & $21.8 \pm 2.9^{+, \neq}$ & $75.2 \pm 2.2 *$ \\
\hline ZF-PA & 177 & $11(6.3 \pm 0.8)^{*,+, \neq}$ & $133(76.6 \pm 5.6)^{t, \pm, \S}$ & $77(57.8 \pm 4.5)^{\neq, \S}$ & $45(33.8 \pm 1.9)^{\ddagger}$ & $25.7 \pm 1.7^{+}$ & $114.3 \pm 7.7^{*}$ & $10.7 \pm 1.4^{*}$ & $89.2 \pm 1.4^{\S}$ \\
\hline \multicolumn{10}{|c|}{$x_{-1}$} \\
\hline ZI-IVF & 173 & $4(2.4 \pm 0.6)^{*}$ & $124(73.7 \pm 5.4)^{*, t, t, \S}$ & $78(62.4 \pm 3.4)^{\S}$ & $53(42.1 \pm 2.3)^{\ddagger}$ & $30.8 \pm 0.5^{+}$ & $149.5 \pm 19.3^{*,+}$ & $21.0 \pm 1.8^{+, \neq}$ & $78.9 \pm 1.8^{*,+}$ \\
\hline ZF-IVF & 167 & $19(11.4 \pm 0.3)^{\neq, \S}$ & $140(84.1 \pm 3.7)^{\neq, \S}$ & $76(53.3 \pm 3.9)^{\ddagger, \S}$ & $43(30.7 \pm 1.2)^{\ddagger}$ & $25.9 \pm 2.1^{\dagger}$ & $125.0 \pm 10.0^{*}$ & $16.3 \pm 1.3^{+, \neq}$ & $83.6 \pm 1.3^{t, \neq, \S}$ \\
\hline
\end{tabular}

Cleavages were assessed based on total number of oocytes. Values with at least one common symbol are not significantly different at $P<0.05$. aMeasured as the percentages of blastocysts developed based on the total number of cleaved oocytes. ${ }^{b}$ Efficiency of blastocyst development, calculated based on the number of blastocyst developed per total number of oocytes used in three replicates in each group.

Zona removal did not affect the potential of parthenogenetic (PA) and IVF embryos to cleave and further develop to blastocysts. Irrespective of the presence (ZI)/absence (ZF) of zona, total blastocyst development and efficiency of blastocyst development in IVF (ZI/ZF-IVF) and PA (ZI/ZF-PA) groups were significantly higher than in all SCNT groups (Table 1 ). Moreover, comparing between IVF, PA and the three SCNT methods, the highest survival rate of oocytes was observed in ZI-IVF oocytes, which was significantly higher than for all the other groups, except the ZI-PA and ZF-PA groups.

Total cell number (TCN) of cloned embryos was not significantly different between the SCNT protocols, but all were significantly lower than that for ZI-PA (Table 1). Importantly, SCNT protocol had a significant effect on the distribution of cells in the blastocysts (Table 1). Accordingly, the proportion of cells classified as ICM and TE in zona-intact cloned blastocysts derived using the ZI-NT method were significantly different from those for ZF-NT (Table 1 and Fig. 4D $\mathrm{D}_{1-3}$ ). Moreover, ZF-PA blastocysts had smaller ICM compared with ZI-PA and both ZI-IVF and ZF-IVF blastocysts. In contrast, zona removal significantly increased TE:TCN ratio of ZF-PA vs ZI-PA and ZI-IVF embryos (Table 1).

\section{SCNT throughput}

The accuracies of zona-free and zona-intact oocyte enucleation were similar ( 100.0 vs $89.6 \pm 7.4 \%$ respectively). Table 2 summarizes the gains in throughput of reconstructed oocytes per person using different SCNT techniques. As shown, the mean number of oocytes enucleated within $1 \mathrm{~h}$ per se was 132 using zona-free oocytes, which was approximately double than the number of zona-intact oocytes, which could be enucleated (68) by the same person at the same time. Moreover, both nuclear transfer and bulk fusion were quicker to perform using ZF-NT rather than ICI-NT and Zl-NT techniques.

\section{Discussion}

\section{Nuclear transfer protocol affects mRNA abundances of the reconstituted oocytes}

Early embryonic events are orchestrated through posttranscriptional control of mRNAs that have been accumulated during oogenesis (Zuccotti et al. 2008, Vigneault et al. 2009). These maternal mRNA and their related proteins serve the distinct purpose of reprogramming and facilitate early mitotic divisions of the fertilized embryos until broad embryonic genome activation that initiates, for example, at eight-cell stage in sheep (Hosseini et al. 2012b). Importantly, comparative analysis of oocyte transcript profiles has indicated a high degree of conservation even between species with distinct taxonomic relationships (Vallée et al. 2008). Without a doubt these transcripts are pivotal for reprogramming of terminally differentiated somatic cells (Sylvestre et al. 2010) and hence cloning efficiency.

Accordingly, the first point highlighted in this study was that SCNT protocol affects relative mRNA abundances of the recipient oocytes. Given the multistep nature of the SCNT process, we followed stepwise variations occurred in the relative abundances of eight developmentally important genes that are characteristic of different cell functions including pluripotency and reprogramming (POU5F1, GMNN and NPM2), metabolism (ATPase), stress (HSP9OAA1), gap-junction and compaction (GJA1), nuclear remodeling (cyclin-B), and PAPOLA as an important protector of RNA degradation. The results showed that i) enzymatic zona digestion, ii) $C B$ treatment and iii) method of oocyte enucleation did not significantly affect the mRNA pool of the oocyte, whereas NT method did. Given that the only difference between these NT methods was the application of electrical pulse in ZI-NT and ZF-NT methods, one may consider that electrofusion may cause these reductions in mRNA abundances. Gradual consumption of maternal mRNA during embryo development is well documented in mammals (Vigneault et al. 2009). 
A

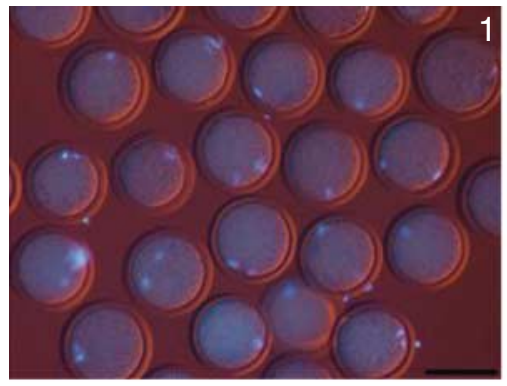

B

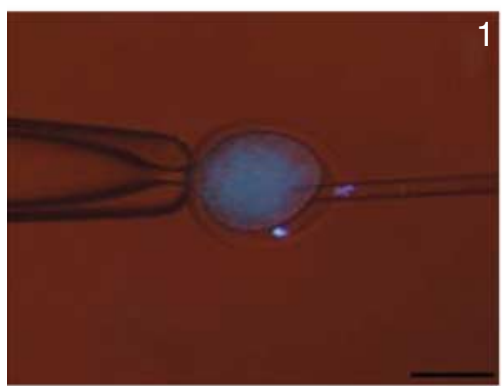

C

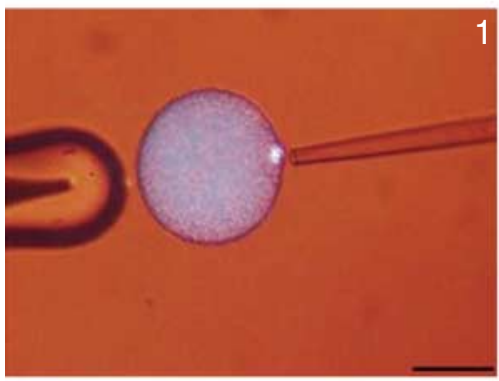

D

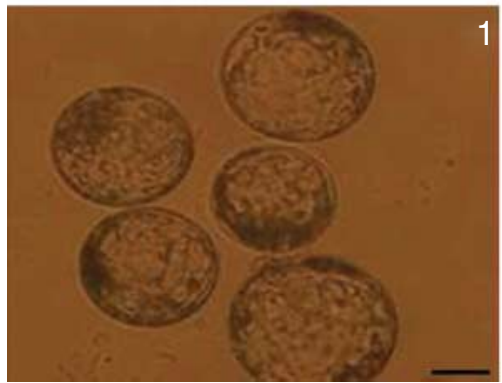

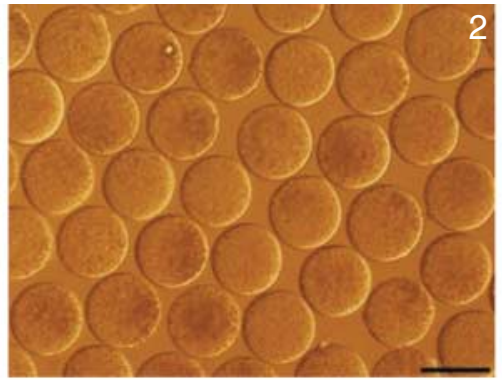
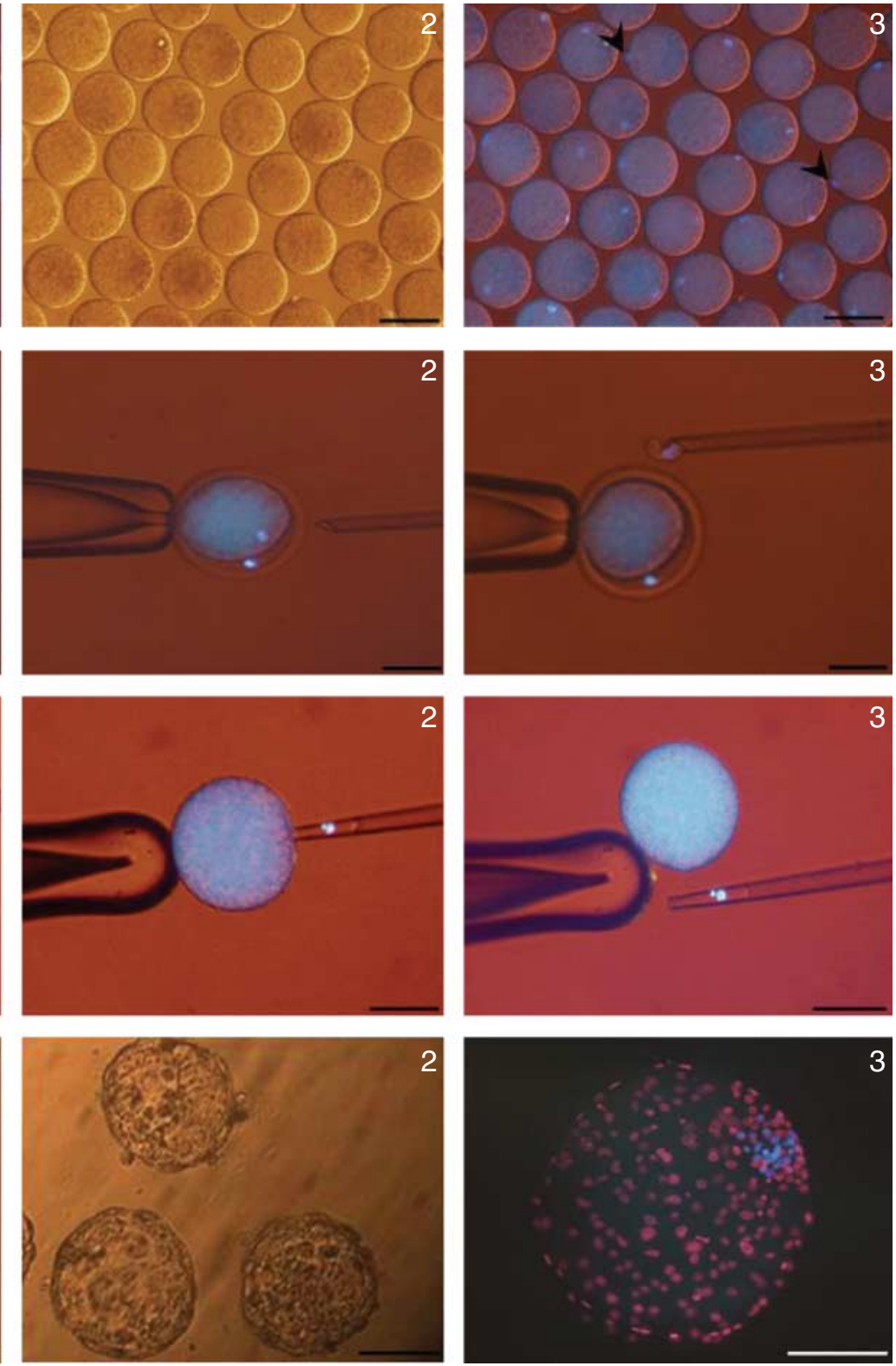

Figure $4\left(A_{1-3}\right)$ H33342-stained in vitro-matured ovine oocytes before zona removal under u.v. light $\left(A_{1}\right)$, and after zona removal under normal $\left(A_{2}\right)$ or u.v. $\left(A_{3}\right)$ light. Arrowheads indicate the cytoplasmic extrusion cone. Steps involved in zona-intact $\left(B_{1-3}\right)$ and zona-free $\left(C_{1-3}\right)$ methods of oocyte enucleation. Representative images of cloned blastocysts developed by zona-intact $\left(D_{1}\right)$ and zona-free $\left(D_{2}\right)$ methods of SCNT and differential staining of a ZI-NT blastocyst $\left(\mathrm{D}_{3}\right)$ are shown. Bar represents $100 \mu \mathrm{m}$.

Moreover, abrupt reduction of oocyte mRNA in response to intensive stresses such as cryopreservation has been established (Asgari et al. 2011, Hosseini et al. 2012a). However, there is no, to our knowledge, previous information about the effect of electric pulses on oocyte mRNA. Therefore, whether this reduction in mRNA is an early direct effect of electrofusion or a subsequent indirect effect of oocyte activation remains to be elucidated.

POU5F1 is the most important hallmark of reprogramming and pluripotency, and the presence of POU5F1 mRNA has been demonstrated in oocytes of different species including human (Hansis et al. 2001), cattle
(Vigneault et al. 2009), but is already demonstrated in sheep. Importantly, Zuccotti et al. (2008) demonstrated that maternal pool of POU5F1 regulates the cascade of molecular pathways that 'govern the establishment of the maternal legacy of MII oocytes required for the transition from a gametic to an embryonic control of development'. Their data provide some indications for maternal POU5F1 as a potential key regulator of developmental competence in mice. NPM2 is a major regulator of sperm and somatic cell chromatin decondensation (Tamada et al. 2006). Importantly, by NPM2 injection into reconstituted bovine oocytes, 
Table 2 Comparison in throughput between the three SCNT methods in sheep.

\begin{tabular}{lcccccc}
\hline & \multicolumn{3}{c}{$\begin{array}{c}\text { Throughput per person } \\
\text { (NT reconstructs/h) }\end{array}$} & & \multicolumn{2}{c}{$\begin{array}{l}\text { Increased throughput } \\
\text { of ZF-NT method vs }\end{array}$} \\
\cline { 2 - 3 } \cline { 7 - 7 } SCNT steps & ICI-NT & ZI-NT & ZF-NT & & ICI-NT & ZI-NT \\
\hline Enucleation & 68 & 68 & 132 & & $1.9 \times$ & $1.9 \times$ \\
Addition of donor cell & 40 & 55 & 150 & & $3.8 \times$ & $2.7 \times$ \\
Fusion & - & 60 & 120 & & - & $2.0 \times$ \\
Total (steps 1-3) & 25 & 20 & 44 & & $2.0 \times$ & $1.7 \times$ \\
\hline
\end{tabular}

Betthauser et al. (2006) observed upregulation of over 200 genes in cloned embryos, which provided embryos with genetic profiles more similar to those of embryos produced by IVF and higher pregnancy rate compared with non-NPM2-injected oocytes. GMNN is another important gene that is highly expressed in oocytes with an important role in cell differentiation of early embryos (Gonzalez et al. 2006, Yang et al. 2011). Therefore, it is plausible to say that the maternal contribution of crucial transcripts and proteins that have been inherited in the oocyte may have critical role in developmental competence of the resulting embryo.

\section{SCNT protocol affects developmental competence of the reconstituted sheep oocytes}

In vitro, the ultimate readout of cloning efficiency is the ability of cloned embryos to develop into blastocysts. Accordingly, the results of this study indicated a marked effect of SCNT technique on developmental competence of the cloned embryos, as the blastocyst yield of ICI-NT was significantly higher than that of ZF-NT. By definition, the most important differences between ICI-NT and ZF-NT methods in this study are i) kinetics of remodeling events, ii) the absence of zona in ZF-NT, and iii) significantly reduced mRNA abundances of oocyte's POU5F1 and PAPOLA in ZF-NT. Moreover, we previously showed that the most important challenge for zona-free embryos is blastomere loss during precompaction stage (Nasr-Esfahani et al. 2011). To evaluate this hypothesis here, in vitro development of zona-intact and zona-free PA and IVF embryos were compared, and interestingly, no significant difference was observed between the blastocyst yields of these groups. Therefore, while the exact reason for lower in vitro development of zona-free cloned embryos remains to be clearly elucidated, two suggested explanations are i) reduction in relative abundances of important maternal mRNA of POU5F1 (Zuccotti et al. 2008) and ii) species-specific differences in technical preferences of SCNT protocol.

\section{SCNT protocol affects cell fate determination of cloned sheep embryos}

During mammalian embryo development, the first-cell lineage specification is the formation of ICM and TE in the blastocyst (Marikawa \& Alarcón 2009). These distinct cell fates distinguish pluripotent ICM cells, which ultimately generate all the tissues in the animal body, from differentiating TE cells that form fetal placenta (Zernicka-Goetz et al. 2009). While the importance of this initial cell differentiation for further development of the embryo is well documented, the exact time-window and mechanism governing the allocation of cells to ICM and TE is a matter of serious debate. Even though the results of this study indicated that SCNT protocols had variable effects on ICM:TE ratios of the developed blastocysts. However, considering some important studies on the possible effects of zona on cell fate determination of early embryo, we carried out further experiments using PA and IVF embryos to unravel the possible crucial importance of zona for cell fate determination. The results were not consistent and did not show the same trend of zona effect on cell fate for PA and IVF. While zona removal significantly switched the cell fate of PA embryos from ICM toward TE formation, the zona had a minor effect on cell fate of IVF embryos. The confusion increases when we observed reports that are for (Kurotaki et al. 2007) and against (Gardner 2007) the impact of zona on cell fate. For example, Katayama et al. (2010) believed that zona removal provided embryos with a high degree of plasticity in response to the orientation of their first two cleavage planes. On the other hand, using zona-intact and zona-free mouse embryos, Gardner (2007) demonstrated that embryonic-abembryonic axis of the mouse blastocyst is normally prepatterned and suggested no role for zona in its specification. Therefore, while the effect of zona on cell fate of sheep embryos remains to be obtained, in the absence of confirmative evidence of zona effect on cell fate, and considering the crucial impact of POU5F1 in the formation of ICM in mice (Dietrich \& Hiiragi 2007), one may argue that the reduction of maternal POU5F1 in oocytes reconstituted using ZI-NT and particularly ZF-NT methods of SCNT may contribute to the lower number of ICM cells in the ZF-NT vs ICI-NT cloned embryos. Further studies to confirm this are necessary.

\section{SCNT protocol, choosing throughput or efficiency?}

Increased potential applications of SCNT have resulted in a parallel increased interest in development of cloning methods that are improved in both efficiency and ease of operation (Oback et al. 2003). Accordingly, the most dramatic changes in cloning technologies were first achieved in cattle, in which zona-free-based methods of Oback et al. (2003) provided a twofold increase in throughput compared with conventional methods. Through modification of different steps, we could also develop a goat-specific zona-free SCNT protocol that improved both throughput and efficiency compared with 
all previous studies (Nasr-Esfahani et al. 2011). In contrast, the ZI-NT approach in this study could not reach such a point of success in both throughput and efficiency. Indeed, zona removal considerably facilitated the enucleation step and significantly increased the speed and efficiency of donor cell addition and cell fusion compared with ICI-NT and ZI-NT methods. However, there was a marked reduction in the yield of zona-free-derived blastocysts compared with two other approaches. This contradiction between efficiency and throughput has raised the question of which criterion is more important: throughput or efficiency? Therefore, we investigated the efficacy of blastocyst production based on the total number of oocytes used in each approach. It was observed that despite higher blastocyst yields of ICI-NT rather than ZF-NT, the efficiency of cloned blastocyst development was not significantly different between the groups. This was due to the higher number of oocytes that were degenerated or fragmented during different steps of ICI-NT compared with ZF-NT. In this situation, one may prefer to choose ZF-NT as a simpler and faster technique of SCNT compared with conventional zona-intact methods. In agreement, Wilmut (2003) stated that the basic routines of zona-free SCNT can be mastered in 3 weeks by a person with no previous experience of micromanipulation, an advantage that is in stark contrast with the time and effort required to master the conventional zona-intact SCNT technique. By looking to these results and to the history of technical advancement of SCNT, one may argue that zona-free SCNT methods may be eventually considered the method of choice.

We obtained successful live birth from cloned sheep embryos derived using ICI-NT and ZI-NT (Kazemi-Ashtiani et al. 2008). Moreover, ZF-NT resulted in the live birth of transgenic and non-transgenic clones in cattle and goats (Nasr-Esfahani et al. 2011) and term pregnancy of an endangered wild sheep using interspecies cloning (Hajian et al. 2011). However, there is yet a place to compare the efficiency of the three techniques in a single study.

\section{Concluding remarks}

This study could provide a direct comparison between three common methods of SCNT in sheep. From a technical point of view, enucleation of zona-free oocytes was easy to perform in lesser time compared with zonaintact ones. Secondly, highly efficient fusion of large pool of oocytes reduced both the time and the number of oocytes, which subsequently resulted in similar cloning efficiency compared with zona-intact methods. These results lead to a final conclusion that SCNT protocols have disparate effects on different aspects of cloned embryo development in vitro, and the most important effect was the different phenotypes of cloned embryos.

\section{Materials and Methods}

\section{Chemicals and media}

Unless specified, all chemicals and media were obtained from Sigma Chemical Co. and Gibco respectively.

\section{Recipient oocytes}

Abattoir-derived ovine oocytes were used for in vitro maturation (IVM) as described previously (Hosseini et al. 2012a). In brief, cumulus-oocyte complexes (COCs) were aspirated from antral follicles (2-6 mm diameter) using 20 gauge needles attached to a vacuum pump $(80 \mathrm{mmHg})$. COCs with more than three layers of cumulus cells were selected and washed first in HEPES tissue culture medium 199 (HTCM199) plus $10 \%$ self-prepared sheep serum and then in maturation medium before being cultured in the maturation droplets $(10-15 \mathrm{COCs} / 100 \mu \mathrm{l})$ under mineral oil at $38.5{ }^{\circ} \mathrm{C}, 6 \% \mathrm{CO}_{2}$, and humidified air. Maturation medium was TCM199 containing $2.5 \mathrm{mM} \mathrm{Na}$-pyruvate, $1 \mathrm{mM}$ L-glutamine, $100 \mathrm{IU} / \mathrm{ml}$ penicillin, $100 \mu \mathrm{g} / \mathrm{ml}$ streptomycin, $10 \%$ sheep serum, $10 \mu \mathrm{g} / \mathrm{ml}$ ovine $\mathrm{FSH}, 10 \mu \mathrm{g} / \mathrm{ml}$ ovine $\mathrm{LH}, 1 \mu \mathrm{g} / \mathrm{ml}$ estradiol-17 $\beta, 100 \mu \mathrm{g} / \mathrm{ml}$ EGF and $0.1 \mathrm{mM}$ cysteamine. At $22-24 \mathrm{~h}$ post-IVM, oocytes were denuded from expanding cumulus cells and only the oocytes with homogenous cytoplasm and first polar body extruded were used for subsequent studies.

\section{Somatic cells}

A skin biopsy was prepared from one healthy adult ram and used for in vitro culture of fibroblasts as described previously (Hosseini et al. 2008). In brief, the biopsy was cut into small explants $\left(2-3 \mathrm{~mm}^{2}\right)$ before being cultured in DMEM/F-12 containing $10 \%$ sheep serum and $1 \%$ penicillin-streptomycin at $38.5^{\circ} \mathrm{C}$ in a humidified atmosphere of $5 \% \mathrm{CO}_{2}$ until confluence. Fibroblast phenotype was verified via an immunostaining method described previously (Jafarpour et al. 2011). To obtain a presumptive G0/G1 population of cells for NT, cells were first cultured at $2.5 \times 10^{4} \mathrm{cells} / \mathrm{cm}^{2}$ and on the next day, the cells were washed three times with PBS before being cultured in medium that contained $0.5 \%$ sheep serum for $4-5$ days.

\section{SCNT experiments}

Oocyte enucleation

Zona-intact oocytes. Denuded oocytes were incubated in HEPES synthetic oviductal fluid free of calcium and magnesium $\left(\mathrm{HSOF}^{-}\right)$containing $\mathrm{CB}(7.5 \mu \mathrm{g} / \mathrm{ml})$ and $\mathrm{H} 33342$ for $15 \mathrm{~min}$ at normal culture condition of matured oocytes described earlier. As shown in Fig. $4 \mathrm{~B}_{1-3}$, enucleation was performed by aspirating a small quantity of cytoplasm directly beneath the first polar body using a beveled (5-10 $\mu$ m outside diameter) glass pipette under an inverted microscope (Olympus IX71) equipped with Narishige micro-manipulator system. Successful enucleation was confirmed by brief exposure of the expelled cytoplasm to fluorescent light to observe MII chromosomes. 
Zona-free oocytes. The procedure of zona-free enucleation was as described previously (Oback et al. 2003) with minor modifications. In brief, zona was removed by brief incubation (up to $2 \mathrm{~min}$ ) of the oocytes with $2.5 \mathrm{mg}$ pronase/ $\mathrm{ml}$ dissolved in $\mathrm{HSOF}$ containing $5 \%$ sheep serum. Interestingly, as shown in Fig. $4 \mathrm{~A}_{1-3}$, after zona removal, a cone-like cytoplasmic extrusion was observed in $50 \%$ of zona-free oocytes. $\mathrm{H} 33342$ staining showed that this cytoplasmic extrusion contains metaphase plate, a sign that was not observed in zona-intact oocytes. Therefore, this cytoplasmic extrusion was used as an aid for enucleation. $\mathrm{H} 33342$ stain was used for confident enucleation of zona-free oocytes. As shown in Fig. $4 \mathrm{C}_{1-3}$, the metaphase plate was removed using a blunt enucleation pipette $(5-10 \mu \mathrm{m}$ outer diameter, perpendicular break) and a blind separation needle. In each approach the mean volume of cytoplasm removed was recorded as described elsewhere (Nasr-Esfahani et al. 2011).

\section{Nuclear transfer}

Conventional (zona-intact) method (ZI-NT). Individual fibroblast cells were aspirated into the injection pipette and introduced through the same slit in the zona (performed during enucleation) and wedged between the zona and the cytoplasmic membrane, to facilitate close membrane contact between donor cell and cytoplast.

Intracytoplasmic injection method (ICI-NT). Donor cells were picked up in $\mathrm{HSOF}^{-}$droplets containing $3 \%(\mathrm{w} / \mathrm{v})$ polyvinylpyrolidone using a transfer pipette that was narrow enough to isolate the nuclei. The method of cell insertion into the cytoplasm of the oocyte was similar to that described by Lee et al. (2003). Owing to critical susceptibility of ovine oocytes to spontaneous activation and fragmentation (Loi et al. 1998), care was taken to transfer the donor cell content with the minimum amount of the media into the oocyte.

Standard zona-free method (ZF-NT). As described by Oback et al. (2003), nuclear donor cells were suspended in HSOF in $5 \mathrm{ml}$ centrifuge tubes, and through making serial dilutions in three to four droplets, a population of 10-20 individual cells was added to a drop of $10 \mathrm{mg} / \mathrm{ml}$ phytohemagglutinin (PHA-P) in HSOF. Oocytes were then individually picked up and gently pushed over a single cell to adhere to it.

\section{Electrofusion, chemical activation, and embryo culture}

The integration of donor cell cytoplast was induced via electrofusion in ZI-NT and ZF-NT methods of SCNT as described elsewhere (Hosseini et al. 2006). In brief, reconstituted oocytes were first equilibrated in fusion buffer $(0.3 \mathrm{M}$ mannitol, $100 \mu \mathrm{M}$ $\mathrm{MgSO}_{4}, 50 \mu \mathrm{M} \mathrm{CaCl}_{2}, 500 \mu \mathrm{M} \mathrm{HEPES}$ and $0.05 \% \mathrm{BSA}$ ) for up to $1 \mathrm{~min}$. Then, couplets were located in a fusion chamber ( $0.5 \mathrm{~mm}$ apart electrodes) filled with fusion medium. The couplets were first aligned manually and then using sinusoidal electric current $(7 \mathrm{~V}$ for $30 \mathrm{~s})$ and then fused with two direct currents of electric pulses $(1.75 \mathrm{KV} / \mathrm{cm}$ for $80 \mu \mathrm{s}$ and $1 \mathrm{~s}$ delay; Cryologic, Mulgrave, Victoria, Australia). Fused couplets were incubated for up to $4 \mathrm{~h}$ in modified synthetic oviductal fluid (mSOF) before chemical activation using an ovinespecific activation protocol described previously (Hosseini et al. 2012a). In brief, reconstituted oocytes were first incubated with $2.5 \mu \mathrm{M}$ ionomycin for $1 \mathrm{~min}$, inactivated by several washes in $30 \mathrm{mg} / \mathrm{ml}$ BSA dissolved in HSOF and finally incubated in 6-dimethylaminopurine (2 $\mathrm{mM})$ for $2 \mathrm{~h}$.

Activated couplets were cultured in groups of ten in $20 \mu \mathrm{l}$ droplets of mSOF containing $5 \%$ sheep serum and $8 \mathrm{mg} / \mathrm{ml}$ BSA for 7 days. The basic formulation of SOF was based on that used in the study of Tervit et al. (1972), with further modifications described elsewhere (Hajian et al. 2011). To preclude aggregation of zona-free embryos to each other and also in order to facilitate their group culture, the wells of the wells system of zona-free embryo culture was applied (Vajta et al. 2000). Culture conditions were $39^{\circ} \mathrm{C}, 5 \% \mathrm{O}_{2}, 5 \% \mathrm{CO}_{2}$, and maximum humidity.

In this study, zona-intact and zona-free parthenogenesis and IVF were considered as controls. The method of PA was the same as the protocol used for artificial chemical activation of cloned embryos. The process of IVF was as described previously (Hosseini et al. 2012a). In brief, frozen ram semen straws were thawed in warm water bath $\left(37^{\circ} \mathrm{C}\right)$ and cryoprotectants were removed by centrifugation $(10 \mathrm{~min}$ at $700 \mathrm{~g}$ at RT). The pellet was layered on 45:45 ratio of Puresperm (Nidacon, Gothenburg, Sweden) and centrifuged at $700 \mathrm{~g}$ for $15 \mathrm{~min}$ to isolate highly motile spermatozoa. Forty to 50 IVM COCs were then incubated with $4 \times 10^{5} 200 \mu \mathrm{l}$ spermatozoa in a droplet of IVF at $39^{\circ} \mathrm{C}, 5 \% \mathrm{CO}_{2}$ in humidified air for $24 \mathrm{~h}$. Presumptive zygotes in groups of ten were then cultured in $20 \mu \mathrm{l}$ droplets of mSOF. Developed blastocysts in different groups were used for differential staining as described by Moulavi et al. (2006).

\section{Nuclear remodeling}

Stepwise assessment of nuclear remodeling was assessed at 2-6 hpr as described previously (Asgari et al. 2011). In brief,

Table 3 Specific primers used in this study.

\begin{tabular}{llcc}
\hline Gene & Primer sequences $\left(\right.$ forward and reverse; $\left.5^{\prime}-3^{\prime}\right)$ & Length $(\mathrm{bp})$ & Annealing temperature $\left({ }^{\circ} \mathrm{C}\right)$ \\
\hline GJA1 $(1)$ & TCGTGTCGTTGGTGTCTCTTGGAGGAGCAGCCATTGAAATAAGC & 175 & 61 \\
Cyclin-B $(2)$ & GATTGGAGAGGTTGATGTTGAGAGGTAATGCTGTAGAGTTGGTG & 172 & 62 \\
Na/K ATPase & GCTGACTTGGTCATCTGCAACATTCCAGGGCAGTAGGAAA & 128 & 58 \\
HSP9OAA1 & GCATTCTCAGTTCATTGGCTATCCTTCTATCTCGGGCTTGTCATCAG & 175 & 61 \\
POU5F1 & AGAAGGGCAAACGATCAAGCGAATGGGACCGAAGAGTACAGAGT & 169 & 62 \\
GMMN & TGGCAGAGATGATACAGAGGGAACTACAGCGGAGGTAAAC & 223 & 58 \\
NPM2 & GAGGAAGTGGAAGAGGAGGATGCAGGGCTCCCTTTAAGATGGTG & 202 & 51 \\
PAPOLA & GAACTTGCCAGCTTTATCCATTGTGGGTATGCTGGTGTAA & 201 & 60 \\
GAPDH & TGCCGCCTGGAGAAACCTGAAGTCGCAGGAGACAACC & 121 & 50 \\
B-Actin & CCATCGGCAATGAGCGGTCGTGTTGGCGTAGAGGTC & 146 & 59 \\
\hline
\end{tabular}


reconstituted oocytes were fixed in $4 \%$ paraformaldehyde for $15 \mathrm{~min}$. Microtubules were immunostained with anti$\beta$-tubulin monoclonal primary antibody (1:100) and FITClabeled anti-mouse-IgG secondary antibody (1:100). The chromosomes were counterstained with $2 \mu \mathrm{g} \mathrm{H} 333242 / \mathrm{ml}$ and then samples were washed and mounted on glass slides in glycerol droplets to be observed using epifluorescence microscope (Olympus BX51) at $400 \times$ magnification. Upon exposure, a digital image of each sample was taken with a high sensitive camera (Olympus DP-72) operated on DP2-BSW Software.

\section{qCRT-PCR}

Relative mRNA abundances of eight developmentally important genes (Table 3) were analyzed. For this purpose, 20 oocytes were collected 30-40 min after each manipulation (described in Fig. 3) in each replicate. After several washes in PBS, oocytes in minimum volume of PBS were transferred to RLT (Qiagen) buffer and stored in $-70{ }^{\circ} \mathrm{C}$ until use. Total RNA of oocytes was extracted using the RNeasy Micro Kit (Qiagen). Then 300 ng of each RNA samples was used for the first-strand cDNA synthesis with RevertAid First Strand cDNA Synthesis Kit (Fermentas, St.Leon-Rot, Germany). cDNA synthesis reactions contained $1 \mu \mathrm{l}$ random hexamer primer $(0.2 \mu \mathrm{g} / \mu \mathrm{l}) 1 \mu \mathrm{l}$ RNase inhibitor $(20 \mathrm{U} / \mu \mathrm{l}), 4 \mu \mathrm{l} 5 \times$ reaction buffer, $2 \mu \mathrm{l} \mathrm{dNTP} \operatorname{mix}(10 \mathrm{mM})$ and $1 \mu \mathrm{l} \mathrm{M-MuLV}$ reverse transcriptase $(200 \mathrm{U} / \mu \mathrm{l})$. Final volume was adjusted up to $20 \mu \mathrm{l}$ by adding diethylpyrocarbonate (DEPC)-treated water. cDNA synthesis was performed by incubation for $5 \mathrm{~min}$ at $25^{\circ} \mathrm{C}$ followed by $60 \mathrm{~min}$ at $42{ }^{\circ} \mathrm{C}$ and terminated by heating at $70{ }^{\circ} \mathrm{C}$ for $5 \mathrm{~min}$. The real-time RT-PCR was carried out using the Corbett Rotor Gene 6000 (Qiagen). Each reaction mix contained $25 \mathrm{ng}$ cDNA, $10 \mu \mathrm{l}$ SYBR Premix Ex Taq II ( $2 \times$; Takara, Otsu, Shiga, Japan), and $1 \mu$ l of each the forward and reverse primers $(5 \mu \mathrm{M})$ adjusted to a total volume of $20 \mu \mathrm{l}$ using nuclease-free water. All reactions were performed in triplicate and normalized to two housekeeping genes (GAPDH and $\beta$-actin). All data were analyzed by $\Delta \Delta C t$ method. For each of the cDNA samples, three replicate PCRs were carried out.

\section{Statistical analysis}

Percentage data were modeled to the binomial model of parameters by ArcSin transformation and the transformed data were analyzed by one-way ANOVA model of SPSS-17. Differences were compared by Tukey multiple comparison post hoc test. All data were presented as means \pm S.E.M. and differences considered as significant at $P<0.05$. Additional experiments were carried out in this study to provide adequate blastocysts for differential staining.

\section{Declaration of interest}

The authors declare that there is no conflict of interest that could be perceived as prejudicing the impartiality of the research reported.

\section{Funding}

This study was funded by the grant of Royan Institute of IRI.

\section{Author contribution statement}

S M Hosseini and $\mathrm{MH}$ Nasr-Esfahani conceived and designed the experiments and wrote the paper and $\mathrm{F}$ Moulavi, S M Hosseini, M Hajian, M Forouzanfar, S Ostadhosseini, $\mathrm{P}$ Abedi and $\mathrm{V}$ Asgari performed the experiments.

\section{Acknowledgements}

The authors would like to gratefully thank Mrs Mansouri and Dr Jafarpour for statistical analysis of data and Mr Heidari and Mr Khajo for ovary preparation.

\section{References}

Asgari V, Hosseini SM, Ostadhosseini S, Hajian M \& Nasr-Esfahani MH 2011 Time dependent effect of post warming interval on microtubule organization, meiotic status, and parthenogenetic activation of vitrified in vitro matured sheep oocytes. Theriogenology 75 904-910. (doi:10.1016/j.theriogenology.2010.10.033)

Betthauser JM, Pfister-Genskow M, Xu H, Golueke PJ, Lacson JC, Koppang RW, Myers C, Liu B, Hoeschele I, Eilertsen KJ et al. 2006 Nucleoplasmin facilitates reprogramming and in vivo development of bovine nuclear transfer embryos. Molecular Reproduction and Development 73 977-986. (doi:10.1002/mrd.20493)

Dietrich JE \& Hiiragi T 2007 Stochastic patterning in the mouse pre-implantation embryo. Development 134 4219-4231. (doi:10.1242/ dev.003798)

Gardner RL 2007 The axis of polarity of the mouse blastocyst is specified before blastulation and independently of the zona pellucida. Human Reproduction 22 798-806. (doi:10.1093/humrep/del424)

Gonzalez MA, Tachibana KE, Adams DJ, van der Weyden L, Hemberger M, Coleman N, Bradley A \& Laskey RA 2006 Geminin is essential to prevent endoreduplication and to form pluripotent cells during mammalian development. Genes and Development 15 1880-1884. (doi:10.1101/ gad.379706)

Hajian M, Hosseini SM, Forouzanfar M, Abedi P, Ostadhosseini S, Hosseini L, Moulavi F, Gourabi H \& Shahverdi AH 2011 "Conservation cloning" of vulnerable Esfahan mouflon (Ovis orientalis isphahanica): in vitro and in vivo studies. European Journal of Wildlife Research 57 959-969. (doi:10.1007/s10344-011-0510-5)

Hansis C, Tang YX, Grifo JA \& Krey LC 2001 Analysis of Oct-4 expression and ploidy in individual human blastomeres. Molecular Human Reproduction 7 155-161. (doi:10.1093/molehr/7.2.155)

Hosseini SM, Hajian M, Moulavi F, Shahverdi AH \& Nasr-Esfahani MH 2006 Optimized combined electrical and chemical activation of in vitro matured bovine oocytes. Animal Reproduction Science 108 122-133. (doi:10.1016/j.anireprosci.2007.07.011)

Hosseini SM, Moulavi F, Foruzanfar M, Hajian M, Abedi P, RezazadeValojerdi M, Parivar K, Shahverdi AH \& Nasr-Esfahani MH 2008 Effect of donor cell type and gender on the efficiency of in vitro sheep somatic cell cloning. Small Ruminant Research 78 162-168. (doi:10.1016/j.smallrumres.2008.06.004)

Hosseini SM, Asgari V, Ostadhosseini S, Hajian M \& Nasr-Esfahani MH 2012 a Specific activation requirements of in vitro matured sheep oocytes following vitrification-warming. Molecular Reproduction and Development 79 434-444. (doi:10.1002/mrd.22047)

Hosseini SM, Hajian M, Foruzanfar M, Moulavi F, Ostadhosseini S, Abedi P, Asgari V, Abbasi H, Tanhaie S, Jafarpour F et al. 2012b Enucleated ovine oocyte supports human somatic cells reprogramming back to the embryonic stage. Cellular Reprogramming 4 155-163. (doi:10.1089/ cell.2011.0061)

Jafari S, Hosseini SM, Hajian M, Forouzanfar M, Jafarpour F, Abedi P, Ostadhosseini S, Abbasi H, Gourabi H, Shahverdi AH et al. 2011a 
Improved in vitro development of cloned bovine embryos using $S$-adenosylhomocysteine, a non-toxic epigenetic modifying reagent. Molecular Reproduction and Development 78 576-584. (doi:10.1002/ mrd.21344)

Jafari S, Hosseini SM, Hajian M, Forouzanfar M, Jafarpour F, Abedi $P$, Ostadhosseini S, Abbasi H, Gourabi H, Shahverdi AH et al. 2011b Epigenetic modification does not determine the time of POU5F1 transcription activation in cloned bovine embryos. Journal of Assisted Reproduction and Genetics 28 1119-1127. (doi:10.1007/s10815-0119638-1)

Jafarpour F, Hosseini SM, Hajian M, Forouzanfar M, Jafarpour F, Abedi P, Ostadhosseini S, Abbasi H, Gourabi H, Shahverdi AH et al. 2011 Somatic cell induced hyperacetylation, but not hypomethylation, positively and reversibly affect the efficiency of in vitro cloned blastocys production in cattle. Cellular Reprogramming 13 483-493. (doi:10.1089/ cell.2011.0005)

Katayama M, Ellersieck MR \& Roberts RM 2010 Development of monozygotic twin mouse embryos from the time of blastomere separation at the two-cell stage to blastocyst. Biology of Reproduction 82 1237-1247. (doi:10.1095/biolreprod.109.082982)

Kazemi-Ashtiani S, Nasr-Esfahani MH, Hosseini SM, Moulavi F, Hajian M, Fouzanfar M, Abedi P, Meamar M, Rezazadeh Valojerdi M, Gourabi H et al. 2008 Royana: successful experience in cloning the sheep. Cell Journal 10 193-200.

Kurotaki Y, Hatta K, Nakao K, Nabeshima Y \& Fujimori T 2007 Blastocyst axis is specified independently of early cell lineage but aligns with the ZP shape. Science 316 719-723. (doi:10.1126/science.1138591)

Latham KE 2005 Early and delayed aspects of nuclear reprogramming during cloning. Biology of the Cell 97 119-132. (doi:10.1042/BC20040068)

Lee JW, Wu SC, Tian XC, Barber M, Hoagland T, Riesen J, Lee KH, Tu CF, Cheng WT \& Yang X 2003 Production of cloned pigs by whole-cell intracytoplasmic microinjection. Biology of Reproduction 69 995-1001. (doi:10.1095/biolreprod.103.015917)

Loi P, Ledda S, Fulka J Jr, Cappai P \& Moor RM 1998 Development of parthenogenetic and cloned ovine embryos: effect of activation protocols. Biology of Reproduction 581177-1187. (doi:10.1095/biolreprod58.5.1177)

Marikawa Y \& Alarcón VB 2009 Establishment of trophectoderm and inner cell mass lineages in the mouse embryo. Molecular Reproduction and Development 76 1019-1032. (doi:10.1002/mrd.21057)

Mitalipov SM, Zhou Q, Byrne JA, Ji WZ, Norgren RB \& Wolf DP 2007 Reprogramming following somatic cell nuclear transfer in primates is dependent upon nuclear remodeling. Human Reproduction 22 2232-2242. (doi:10.1093/humrep/dem136)

Moulavi F, Hosseini SM, Ashtiani SK, Shahverdi A \& Nasr-Esfahani MH 2006 Can Vero cell co-culture improve in-vitro maturation of bovine oocytes? Reproductive Biomedicine Online 13 404-411. (doi:10.1016/ S1472-6483(10)61446-0)

Nasr-Esfahani MH, Hosseini SM, Hajian $M$, Forouzanfar $M$, Ostadhosseini S, Abedi P, Khazaie Y, Dormiani K, Ghaedi K, Forozanfar M et al. 2011 Development of an optimized zona-free method of somatic cell nuclear transfer in the goat. Cellular Reprogramming 13 157-170. (doi:10.1089/cell.2010.0083)

Oback B \& Wells D 2002 Practical aspects of donor cell selection for nuclear cloning. Cloning and Stem Cells 4 169-174. (doi:10.1089/ 153623002320253337)

Oback B, Wiersema AT, Gaynor P, Laible G, Tucker FC, Oliver JE, Miller AL, Troskie HE, Wilson KL, Forsyth JT et al. 2003 Cloned cattle derived from a novel zona-free embryo reconstruction system. Cloning and Stem Cells 5 3-12. (doi:10.1089/153623003321512111)

Peter M, Nakagawa J, Dorée M, Labbé JC \& Nigg EA 1990 In vitro disassembly of the nuclear lamina and $M$ phase-specific phosphorylation of lamins by cdc2 kinase. Cell 18 591-602. (doi:10.1016/00928674(90)90471-P)

Schurmann A, Wells DN \& Oback B 2006 Early zygotes are suitable recipients for bovine somatic nuclear transfer and result in cloned offspring. Reproduction 132 839-848. (doi:10.1530/REP-06-0054)
Sung LY, Shen PC, Jeong BS, Xu J, Chang CC, Cheng WT, Wu JS, Lee SN, Broek D, Faber D et al. 2007 Premature chromosome condensation is not essential for nuclear reprogramming in bovine somatic cell nuclear transfer. Biology of Reproduction 76 232-240. (doi:10.1095/biolreprod. 106.053561)

Sylvestre EL, Pennetier S, Bureau M, Robert C \& Sirard MA 2010 Investigating the potential of genes preferentially expressed in oocyte to induce chromatin remodeling in somatic cells. Cellular Reprogramming 12 519-528. (doi:10.1089/cell.2010.0012)

Tamada H, Van Thuan N, Reed P, Nelson D, Katoku-Kikyo N, Wudel J, Wakayama T \& Kikyo N 2006 Chromatin decondensation and nuclear reprogramming by nucleoplasmin. Molecular and Cellular Biology 26 1259-1271. (doi:10.1128/MCB.26.4.1259-1271.2006)

Tervit HR, Whittingham DG \& Rowson LE 1972 Successful culture in vitro of sheep and cattle ova. Journal of Reproduction and Fertility 30 493-497. (doi:10.1530/jrf.0.0300493)

Vajta G, Peura TT, Holm P, Páldi A, Greve T, Trounson AO \& Callesen H 2000 New method for culture of zona-included or zona-free embryos: the well of the well (WOW) system. Molecular Reproduction and Development 55 256-264. (doi:10.1002/(SICl)1098-2795(200003)55: $3<256:$ :AID-MRD3 $>3.0$. CO;2-7)

Vallée M, Aiba K, Piao Y, Palin MF, Ko MS \& Sirard MA 2008 Comparative analysis of oocyte transcript profiles reveals a high degree of conservation among species. Reproduction 135 439-448. (doi:10.1530/REP-07-0342)

Verma PJ \& Trounson A 2006 Nuclear transfer protocols: Cell reprogramming and transgenesis. Methods in Molecular Biology 346 85-130.

Vigneault C, Gravel C, Vallée M, McGraw S \& Sirard MA 2009 Unveiling the bovine embryo transcriptome during the maternal-to-embryonic transition. Reproduction 137 245-257. (doi:10.1530/REP-08-0079)

Wakayama T, Perry ACF, Zuccotti M, Johnson KR \& Yanagimachi R 1998 Full-term development of mice from enucleated oocytes injected with cumulus cell nuclei. Nature 394 369-374. (doi:10.1038/28615)

Wells DN, Forsyth JT, McMillan V \& Oback B 2004 The health of somatic cell cloned cattle and their offspring. Cloning and Stem Cells 4 101-110. (doi:10.1089/1536230041372300)

Wilmut I 2003 A new era in methods of embryo manipulation? Cloning and Stem Cells 5 1-2. (doi:10.1089/153623003321512102)

Wrenzycki C, Wells D, Herrmann D, Miller A, Oliver J, Tervit R \& Niemann H 2001 Nuclear transfer protocol affects messenger RNA expression patterns in cloned bovine blastocysts. Biology of Reproduction 65 309-317. (doi:10.1095/biolreprod65.1.309)

Yang VS, Carter SA, Hyland SJ, Tachibana-Konwalski K, Laskey RA \& Gonzalez MA 2011 Geminin escapes degradation in G1 of mouse pluripotent cells and mediates the expression of Oct4, Sox2, and Nanog. Current Biology 26 692-699. (doi:10.1016/j.cub.2011.03.026)

Zernicka-Goetz M, Morris SA \& Bruce AW 2009 Making a firm decision: multifaceted regulation of cell fate in the early mouse embryo. Nature Reviews. Genetics 10 467-477. (doi:10.1038/nrg2564)

Zhou Q, Yang SH, Ding CH, He XC, Xie YH, Hildebrandt TB, Mitalipov SM, Tang XH, Wolf DP \& Ji WZ 2006 A comparative approach to somatic cell nuclear transfer in the rhesus monkey. Human Reproduction 21 2564-2571. (doi:10.1093/humrep/del216)

Zuccotti M, Merico V, Sacchi L, Bellone M, Brink TC, Bellazzi R, Stefanelli M, Redi CA, Garagna S \& Adjaye J 2008 Maternal Oct-4 is a potential key regulator of the developmental competence of mouse oocytes. BMC Developmental Biology 8 97. (doi:10.1186/1471-213X-8-97)

Received 14 August 2012

First decision 31 August 2012

Revised manuscript received 28 October 2012

Accepted 28 January 2013 